\title{
THE UNCONSCIOUS:
}

A. Dormant Consciousness (Physiological Residua)
B. Physiological Memories

BY MORTON PRINCE, M.D.

Professor of Diseases of the Nervous System, Tufts College Medical School

CHAPTER I

Conscious and Unconscious Memory

A FTER going through any given mental experience, the elementary ideas composing it give place to other ideas and become dormant. In greater or less measure they may afterwards become resuscitated voluntarily or involuntarily. They are then known as memories. But so long as they are out of mind or forgotten, they are latent or dormant. What becomes of them? They may be revived at any given moment, but until they are revived they do not exist as ideas at all. They have a potential existence and may be likened to potential energy. This comparison may be more than an analogy. It may be that the ideas under discussion are stored up in some form of physiological energy which may later, again, become transformed into conscious energy. Our knowledge of such matters, of course, is not sufficiently deep at present to allow us to find in this conception of potential physiological energy anything more than an hypothesis based on analogy. All we know is that mental complexes out of mind are dormant but can be revived at any given moment under proper stimulation. Such ideas may be likened to the energy manifested by a cluster of electric lights: by the turning of a switch the cluster or complex of carbon filaments suddenly glow with energy; again, at the turning of a switch, the glow disappears, but that electrical complex may, at any moment, be brought again into activity as the light of the same cluster of lamps. The conception of an idea continuing to exist as such without being a state of consciousness (or co-consciousness) is unthinkable, and yet we know by experience that conditions are formed that enable an idea which has been once experienced and has subsided to be 
revived. In subsiding an idea becomes potential, but we have no conception in psychological terms of what such an idea stands for. We can only think of the continuous existence of dormant ideas in terms of the correlated neuron process and imagine that the neuron process underlying thought becomes so influenced and orgałnized that, when re-excited, the correlated ideas arise. Any explanation of dormant ideas, therefore, that is at all intelligible, must be in terms of neuron processes.

Ideas when thus forgotten or put out of mind are by some writers called subconscious. This is an unfortunate and, as I believe, wrong term, for it connotes qualities which the idea does not possess. Any mental state is a state of active consciousness or else it can have no existence, or at any rate, it cannot be conceived as existing. If active, as we have seen, we may or may not be aware of it. If we are not aware of it, it is co-conscious, or if one prefers, subconscious; if we are aware of it, it is a part of our personal conscious system. In either case it is an active conscious state. It may have a greater or less degree of vividness, but whatever its degree of vividness. it is still an active state of consciousness. Now ideas which are forgotten, or out of mind, or are not at the moment recalled, are not ideas nor states of consciousness at all. To speak of such ideas as "subconscious" is to misname them, and leads to confusion of thought and lack of precision in our conceptions. To say that they are "subconscious" implies that there is some element of consciousness attached to them, and this they have not. Yet this is a common use of the term and the inclusion of such ideas within the meaning of "subconscious" is the custom of some writers and permeates popular language. A further strong practical objection to the use of this term to define ideas that are out of mind or forgotten is that it has already been pre-empted by one class of writers as an expression for co-conscious ideas. Janet, the leading exponent of this latter school, has limited the meaning of "subconscious" to ideas that are in actual activity but of which the subject is not aware. His classical researches in hysteria have, therefore, pre-empted the term. I have elsewhere given my reason for insisting that "co-conscious" 
is a more precise term to define ideas of this kind than " subconscious." These two terms, however, are, within this meaning, synonyms, but we cannot transfer the term "subconscious" to an entirely different class of mental phenomena without creating confusion of thought. All we can say is that ideas that have become dormant may be represented by physiological residua in neuron processes. The term "the unconscious" (das Unbewusste), as used by German writers, if strictly adhered to, is more exact. It accurately defines the facts, if restricted to characterize the physiological residua or dispositions which are left by the passing mental processes and are retained in the neuron elements. Unfortunately, however, this term is commonly used as the synonym for "subconscious" and conversely. This is particularly the case with German writers who employ it to define processes of which we are not aware and which might well be interpreted as co-conscious or, at any rate, to describe phenomena which in every way resemble those which experimental research has shown are best interpreted as due to co-conscious activity. "The unconscious" however, is also equally descriptive of those organized physiological processes in lower neuron systems (spinal cord, sympathetic system, etc.) which are not accompanied by consciousness, though, as we shall see, they possess the function of memory and are capable of intelligent automatic action. They are undoubtedly of the same nature as those more highly organized processes of the brain which manifest themselves as consciousness. It is desirable to have, if possible, terms which will distinguish between these two kinds of processes.

Now there are a great many facts which establish the principle that there are physiological memories as well as psychological memories. Memory, of course, derives its signification from psychological experience and, therefore, as popularly understood, involves the element of consciousness. But if we keep in mind the process for which memory stands we find that the conscious element is not essential and that we may apply the term with equal regard for the facts to physiological processes as well as to psychological processes. As' Ribot* has well expressed it: ".... Memory, as

" Diseases of Memory" (English translation), p. 9. 
ordinarily known to us and as psychology commonly describes it, far from comprising the whole process of memory, is only its most highly developed and complex phase, and that, taken by itself and studied alone, it is not easily understood; that it is the last term in a long evolutionary series, the product of an extended, but connected, development, having its origin in organic life; in short, that memory is, per se, a biological fact - by accident, a psychological fact." In short, as Hering* has pointed out, memory is a general function of organized matter. It is not necessary to enter into this principle in any extended way, for it is well recognized that the essential part of memory is the conservation and reproduction of an experience. In the psychological domain the reproduction is of ideas; in the physiological it is of function of neuron processes organized by repeated experiences into a system unaccompanied by consciousness.

We are accustomed to think of memory as consisting in addition to other qualities, of a conscious recollection or localization of an experience in the past; but, as Ribot points out, this is " only a certain kind of memory which we call perfect." More than this, I would insist, it is only a certain kind of conscious memory. Ribot would make recollection a peculiarity of all conscious memory, but this is plainly an oversight. There may be conscious memories which do not contain any element of recollection; or, in other words, conscious memories may be a reproduction of ideas resembling in every way, in principle, the reproduction of organic neuron processes in that they have no conscious localization in the past. In dissociated personalities, for instance, and in other types of dissociated conditions (functional amnesia, post-hypnotic states, etc.) the names of persons, places, faces, objects, and even complex ideas may flash into the mind, without any element of recollection. The person may have no idea whence they come, but by experiment it is easy to demonstrate that they are automatic memories of past experiences. $\dagger$ In the sensory automatisms known as crystal

* "Ueber das Gedächtniss als allgemeine Function der organisirten Materie," 1876.

†Compare "The Dissociation of a Personality," by Morton Prince, pp. 253,261. For examples see also "Multiple Personality," by Boris Sidis; and "The Lowell Case of Amnesia," by Isador Coriat, ThE Journal of Abnormal Psychology, Vol. II, p. 93. 
visions, pictures, which accurately reproduce past experiences but of which the subject has no recollection, may vividly arise in the mind. Such pictures are real conscious memories. Dreams, too, may be unrecognized memories in that they reproduce conscious experiences something heard or seen, perhaps, but which has been completely forgotten even when awake.* Again modern methods of ps fchoanalysis show that heaps of ideas that occur in the course of our every-day thoughts - names, for instance - are excerpts from, or vestiges of previous conscious experiences of which we have no recollection; that is to say, they are memories, reproductions of formerly experienced ideas. In the absence of recollection they seem to belong only to the present. Memories which hold an intermediate place between these automatic memories and those of true recollection are certain memories, like a verse or phrase once learnt by heart which we are able at best only to dimly localize in the past. Indeed the greater part of our vocabulary is but conscious memory without localization in the past.

So we see that recollection is not an essential for even conscious memories. It is only a particular phase of memory just as are automatic conscious memories. Conservation and reproduction are the sole essential qualities of memory and these are functions of all living matter, of the cell as well as of an organized complex of many cells. A cell which once reacts to a given stimulus continues to conserve and reproduce that reaction. Though it is well to recognize the universality of the principle that memory is a biological fact and that it belongs to physiological processes as well as to psychological processes, we need not concern ourselves here with these lower forms.

In the neuron systems memory reaches a high degree of perfection. The neuron organization "faithfully preserves the records of processes often performed " + though exactly

- A relative of mine gave me a very accurate description of a person, whom she had never seen, from 2 dream in which she saw him. She had completely forgotten the fact that a few days before I had described this person to her. Her description was an exact reproduction of mine, including the identical words.

†See for an interesting statement of physiological memory, "On Memory and Specific Energies of Nervous System," by Ewald Hering. The Open Court Pub. Co. 
how these records are made we do not know. In many of the lower animals from which the brain has been removed and which, therefore, we must assume are without consciousness, the spinal cord and its prolongations continue to perform actions originally guided by consciousness. The reptile crawls, the fish swims; indeed the lancet-fish has no brain, all its functions being regulated by the memories of its spinal cord. The frog hops and swims; the hen preens its feathers, walks and flies; the duck and goose swim, the pigeon thrown into the air flies; the dog walks and runs. If a dog, whose spinal cord has been severed so as to cut off all connection with the brain, is extended horizontally in the air the legs may be made to perform the rhythmical movements of walking, trotting, and galloping. (Sherrington; Phillipson).* In many such phenomena there is a reproduction of organized experiences or memory. In man movements acquired volitionally, and perhaps laboriously, are, after constant repetition, reproduced with precision without consciousness. The maintaining of the body in one position, sitting or standing, though requiring a complicated correlation of a large number of muscles, is carried out without conscious volition. It is the same with walking and running. Still more complicated movements are similarly performed in typewriting and playing the piano. The neurons remember or reproduce the process acquired by previous experiences. Precision in games of skill largely depend upon this principle. A tennis player must learn the "stroke" to play the game well. This means that the muscles must be co-ordinated to a delicate adjustment which, once learned, must be unconsciously remembered and used, without consciously adjusting the muscles each time the ball is hit. Indeed some organic memories are so tenacious that a player once having learned the stroke finds great difficulty even by effort of will in unlearning it and making his muscles play a different style of stroke. Likewise

* So far as such movements represent congenital structural and functional arrangemems and are pure reflex actions which are unconditioned by education or experience, it is questionable whether they can be regarded as manifestations of memory. Memory, properly speaking, is conditioned by experience. Many spinal reflex actions, however, such as the "scratch" reflex in the dog, may in the beginning have been organized by conscious of unconscious experience. 
one who has learned to use his arms in sparring by one method finds difficulty in learning to spar by another method under a different teacher.

Between the most complex unconscious physiological process performed by the nervous system and the simpler cerebral processes accompanied by consciousness there is not as wide a step as might seem when superficially viewed. The physiological process may, as we have seen, manifest itself in acts of quite as an intelligent character as those exhibited by the conscious process, and indeed more so; for the conscious act may be little more than a limited reflex. On the psychical side the consciousness may be so elementary that it contains nothing of awareness, of self, of intelligence, or of volition in the true sense - nothing more, perhaps, than an elementary sensation without even perception. But it may be said that the presence of the most rudimentary state of consciousness makes all the difference and the gulf between the two impassable.

I am not prepared to discuss that question here. Certain it is that, objectively viewed, there is nothing to disting uish physiological from psychological memories. If the extraordinary instinctive habits exhibited by insects such as bees and ants, and by still lower forms of animal life, can rightly be interpreted as manifestations of physiological processes, without consciousness, as is quite possible, the distinction between the conscious and the unconscious in respect to memory and adaptability to environment would be reduced to one only of degree. That some of the lowest forms of life are endowed with consciousness, in any sense in which the word has meaning, seems incredible, though they manifest instinctive intelligence of no mean order. The fact probably is that those processes we call physiological and those we call psychical are in their inner nature identical, and the former are quite capable of functioning, incredible as it may seem, in a fashion that we are accustomed to believe can only be the attribute of conscious intelligence. This does not mean, of course, that the physiological intelligence can reach the same degree of perfection as that reached by conscious intelligence, though conversely, conscious intelligence may be of a lower order than physiological intelligence. 
The possibility of organizing physiological processes into memories by education and linking them to psychological processes is shown very neatly by the extremely important experiments of Pawlow and his co-workers on the reflex stimulation of saliva in dogs. It should be explained that it was shown that the salivary glands are selective in their reaction to stimuli in that they do not respond at all to some (pebbles, snow), but respond to others with a thin watery fluid containing mere traces of mucin, or a slimy mucin-holding fluid, according as to whether the stimulating substance is one which the dog rejects and therefore must be washed out or diluted (sand, acids, bitter and caustic substances), or is an eatable substance and must as a food bolus be lubricated for the facilitation of its descent. Dryness of the food, too, largely determined the quantity of the saliva. Now the experiments of the St. Petersburg laboratory brought out another fact which is of particular interest for us, and which is thus described by Pawlow. "In the course of our experiments it appeared that all the phenomena of adaptation which we saw in the salivary glands under physiological conditions, such, for instance, as the introduction of the stimulating substances into the buccal cavity reappeared in exactly the same manner under the influence of psychological conditions - that is to say, when we merely drew the animal's attention to the substances in question. Thus, when we pretended to throw pebbles into the dog's mouth, or to cast in sand, or to pour in something disagreeable, or, finally, when we offered it this or that kind of food, a secretion either immediaetly appeared, or it did not appear, in accordance with the properties of the substance which we had previously seen to regulate the quantity and nature of the juice whne physiologically excited to flow. If we pretended to throw in sand, a watery saliva escaped from the mucous glands; if food, a slimy saliva. And if the food were dry - for example, dry bread - a large quantity saliva flowed out, even when it excited no special interest on the part of the dog. When on the other hand, a moist food was presented - for example, flesh - much less saliva appeared than in the previous case, however eagerly the dog may have desired the food. This latter effect is particularly obvious in the case of the parotid gland."* More than *"The Work of the Digestive Glands" (English Translation), p. 152. 
this the psychical excitation may be part of a wider complex: everything that has been in any way psychologically associated with an object which physiologically excites the saliva reflex may also produce it; the plate which customarily contains the food, the furniture upon which it stands; the person who brings it; even the sound of the voice and sound of the steps of this person.* Such experiments give precision to the common observation of all dog lovers who have noticed the drooling of saliva at the mere suggestion to the dog of food.

Indeed it was found that any sensory stimulus could be educated into one that would induce the flow of saliva, if the stimulus had been previously associated with food which normally excited the flow. "Any ocular stimulus, any desired sound, any odor that might be selected, and the stimulation of any part of the skin, either by mechanical means or by the application of heat or cold, have in our hands never failed to stimulate the salivary glands, although they were all of them at one time supposed to be inefficient for such a purpose. This was accomplished by applying these stimuli simultaneously with the action of the salivary glands, this action having been evolved by the giving of certain kinds of food or by forcing certain substances into the dog's mouth.' $\dagger$ It is obvious that reflex excitation thus having been accomplished by the education of the nerve centers to a previously indifferent stimulus the reproduction of the process through this stimulus is in principle an act of physiological memory. $\neq$

These experiments acquire additional interest from the fact that in them we see the fundamental principle of what under other conditions can be recognized as a psychosis or neurosis - an abnormal or perverted association and memoy. The effects produced by this association of stimuli may be regarded as the germ of the habit psychosis. Indeed it is in the domain of pathology that physiological memories may be studied in some of their neatest and most precise forms.

*a Psychische Erregung der Speicheldrusen." J. P. Pawlow. Ergebnisse der Physiologie, 1904, I abteil. p. 182.

†Huxley Lecture; Br. Med. Jour., Oct. 6, 1906.

$\ddagger$ Pawlow overlooked in these experiments the possible, if not probable, intermediary of the emotions in producing the effects. The principle, however, would not be effected thereby. 
In one form they are known as habit or association neuroses. In a study made some years back* I pointed out that the physiological complexes which constituted such neuroses depended upon the organization, through intense stimulation or repetition, of physiological neuron processes into systems and that it was the reproduction of functioning of such systems which is the neurosis.

These habit neuroses occur in all sorts of forms and involve all the functions of the body. One of the prettiest of these habit neuroses is a type of hay fever. A case which has been frequently quoted is that reported by Dr. MacKensie, of Baltimore. The patient was subject to hay fever in a most intense form brought on by exposure to roses. To demonstrate its functional character on one occasion, at a time when the patient was free from the disease, Dr. MacKensie produced a bunch of roses from behind a screen. At once the patient was thrown into a violent paroxysm in which lachrymation, congestion of the mucous membranes, secretions, dsypnoea, etc., made up the complex. The patient did not know that the roses were made of paper. The interpretation is obvious: the nervous centers had been excited over and over again until the elements had become so strongly organized that the whole reproduced itself like a mechanical mechanism at a given stimulus. The record of the first experience had been retained as a physiological memory which came into activity from moment to moment. A series of similar cases I had an opportunity to observe and study.t

* "Association Neuroses," Jour. Nervous and Mental Diseases, May, .1891. Compare also: "Three cases of Association Neuroses," John E. Donley, M.D., Boston Med. and Surg. Jour., Nov. 3, 1904. "Types of Habit Neuro-Psychoses," E. W. Taylor, M.D., Boston Med. and Surg. Jour., July 21, 1898. "Study of Association Neuroses," John E. Donley, M.D., Journal Aznormal Psychology, Vol. 11, p. 45.

t" Hay Fever, due to Nervous Influences, occurring in five members of the same family," by Morton Prince, M.D., Annals of Gynecology and Pediatrics, 1895 .

I suspect that a very large proportion, larger than is generally supposed, of hay-fever cases are of this habit character and that for this reason many of the so-called climatic cures effected in the Meccas to which such people flock are largely due to the psycho-therapeutic influence of suggestion. 
This principle of the organization of neuron processes into systems or complexes, by which organization the original process is conserved and reproduced from time to time, is so important that I may copy here a diagram which was originally incorporated in the article on association neuroses above referred to. It is designed to show schematically the organization of neuron "centers" in the habit type of hay-fever. The reproduction of such a process is, of course, a physiological memory.

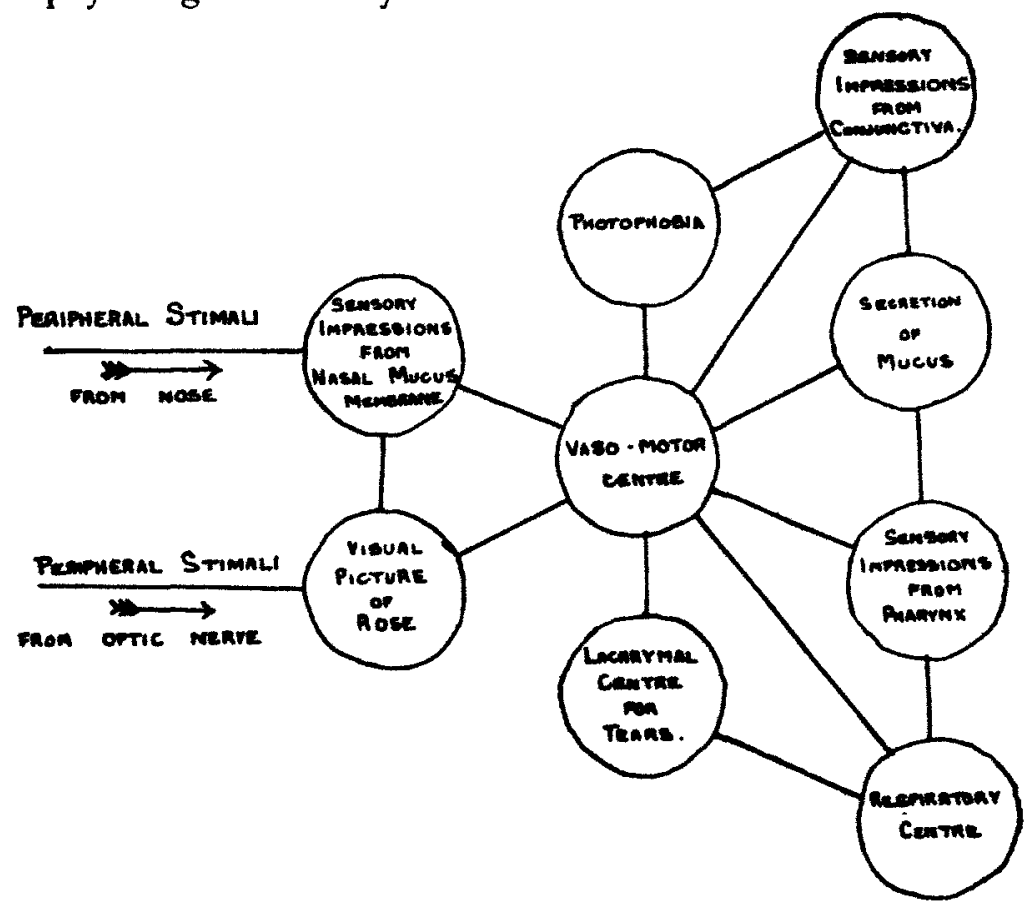

The physiological memories created by the repetition of physiological functions is exemplified in neuroses of all sorts in which organized disease is simulated. Gastric, intestinal, joint, cardiac, ocular, respiratory diseases are thus often mimiced. The recognition of the pathology of such conditions is of the greatest practical importance. If this principle were not true, if physiological memories were not a function of the neuron system, education of every kind, 
from walking to language and feats of skill, would be impossible; we would be unable to acquire any art; but if it is true for actions that fulfil useful and beneficent purposes, it must be true for those that fulfil useless and harmful purposes. The laws of nervous matter are general, not special, and it would be inconceivable that the law should cease to hold equally good for those neuron processes which fulfil undesirable ends. If neuron memories that adapt an individual to his environment are capable of being established under certain conditions, under other conditions memories that misadapt him to his environment are equally capable of being developed. Thus it is that habit or association neuroses arise. In this principle of physiological memories we can correlate habit neuroses, however undesirable and disagreeable, with those other habits which, as accomplishments, we industriously cultivate.

An extension of this principle of organic memory, inherent in nervous matter, to brain processes becomes compulsory if we would be consistent. We are compelled to believe that the principle holds good for neuron processes accompanied by thought as well as for those which are purely organic. We find that our conscious memories correspond in their behavior in every way with physiological memories and follow the same laws. Consequently, if the correlation of the mind with the brain is to be intelligible, we must believe that in all ideation, in every process of thought, the record of the conscious stream may be conserved in the correlated neuron process. The neurons retain residua of the original process, become to a greater or less degree organized and capable of reproducing the original process. When we reproduce the original ideas in the form of memories there is also a reproduction of the physiological neuron process, and vice versa, - but the essential point is that the record of our ideas - ex hypothesi - is retained in the neurons, that though our ideas pass out of mind, are forgotten for the moment and become dormant, their physiological records still remain, as sort of vestigia, much as the records of our thoughts are recorded on the moving wax cylinder of the phonograph. When the cylinder revolves again the 
thoughts once more are reproduced as auditory language. A better analogy would be the recording and reproducing of our thoughts by the dynamic magnetization of the iron wire in the more recently invented instrument. So when the ideas of any given conscious experience become dormant the physiological records, or dynamic rearrangements still remain organized as physiological unconscious complexes, and with the excitation of these physiological complexes the corresponding psychological memories awake. It is only as such physiological complexes that ideas out of mind can be regarded as still existing. As Ribot has well expressed it, ". . Feelings, ideas, and intellectual actions in general, are not fixed, and only become a portion of memory when there are corresponding residua in the nervous system residua consisting, as we have previously demonstrated, of nervous elements, and dynamic associations among those elements. On this condition, and this only, can there be conservation and reproduction."* Dormant ideas are thus equivalent to conserved unconscious physiological complexes. We may use either term to express the fact.

Dormant ideas, however, are not equivalent to physiological memory which means the functioning (reproduction) of physiological complexes that do not manifest consciousness. Memory, strictly speaking, requires more than conservation; memory is reproduction of that which is conserved. It is, therefore, an active functioning process.

We thus have conscious complexes of ideas and their correlated dormant unconscious physiological complexes of organized physical residua. When these latter function they manifest themselves as conscious memories.

The Unconscious then embraces two classes of facts which may be thus tabulated:

A. Cerebral neuron organization and residua (correlated with consciousness and when functioning manifested as conscious memories.)

UNCONSCIOUS

B. Spinal and ganglionic organization and residua (when functioning manifested as physiological memories).

* "Diseases of Memory," by Th. Ribot pp. 154, 155. Translation by William Huntington Smith. D. Appleton \& Co. 
Undoubtedly the inner nature of each class is the same, the cerebral material having a more highly evolved and complex arrangement but the same in kind. Each is capable of reactions which have all the characteristics of intelligence (memory, volition, instinct, etc.), though only one is accompanied by (manifests) consciousness.

I dislike to coin new terms, but a precise terminology helps to precision of thought. I suggest, therefore, that the term Dormant Consciousness will accurately define the mental complexes which have passed out of mind and the unconscious physiological complexes into which they have become transformed, and that, by the use of this term, we shall know exactly what sort of mental states and physiological complexes we are referring to, which will not be the case if the term " subconscious" is used.*

Freud quite correctly defines the status of ideas that are simply out of mind or forgotten as "the unconscious" (das Unbewusste) and to this attributes a considerable role in the production of amnesia and other normal and abnormal phenomena. He does not attempt, however, so far as I have been able to learn, to define the precise character of that which he calls "the unconscious."

As a concept in a scheme of metaphysics, " unconscious ideas," i. e., ideas of which we are not conscious, have long

*I forbear to enter into the question of the nature of consciousness and matter. In the last analysis, matter and mind undoubtedly are to be identified as different manifestations of one and the same great principle - the doctrine of monism - call it spiritual or material as you like, according to your fondness for names. For our purpose it is not necessary to touch this philosophic problem, as we are dealing only with specific biological experiences.

- "It may be opposed that the same objection holds to "dormant consciousness" as to "subconsciousness," in that it is contradictory; for an idea can, not be dormant and also conscious. While this is, strictly speaking, trueyet it is desirable that we should stick to psychological terms if we can do so without confusion of thought; and inasmuch as we are accustomed to speak of our consciousness as being, at times of slumber, asleep or dormant, there is little reason for misunderstanding. "Physiological complex" is a more exact and analytical term, but it is not wholly desirable to translate the term into one of physiology. The chief objection to "subconsciousness" and "the unconscious" is avoided by the term selected, namely, that both are used in many senses by different writers, and the former has been pre-empted by some to designate co-conscious ideas. 
been recognized. Leibnitz was the first to maintain, on theoretical grounds and by $a$ priori reasoning, the existence of ideas of which we are not aware, as did likewise Kant, influenced by Leibnitz, and later Schilling, and Herbart; while Hartmann evolved the unconscious into a biological and metaphysical system.*

In the language of modern psychology, such ideas, as conceived at least by Leibnitz, Kant, and Herbart, would be called subconscious or co-conscious ideas. Hartman included all physiological processes of the nervous system in the Unconscious and ascribed to them special attributes (will, purpose, etc.). The Unconscious accordingly has connotations from which it is not easy to rid ourselves in dealing with it. But aside from its conceptions in philosophy, and restricting the term to its modern psycho-physiological field, it is not clear whether, as employed by the Freud and Zurich schools, it is intended to include only the organized physiological dispositions of Class A, or co-conscious ideas, or both. So far as ty the Unconscious is here meant only the physiological dispositions or residua, above defined, no exception can be taken to the term. Used for this class it is descriptive (for dormant ideas are unconscious) though not

* For an interesting account of the history of the theory of unconscious ideas in philosophy, see Hartmann's "Philosophy of the Unconscious" where the following quotations may be found: "To have ideas and yet not to be conscious of them - there seems to be a contradiction in that; for how can we know that we have them if we are not conscious of them? Nevertheless we may become aware indirectly that we have an idea, although we be not directly cognizant of the same." (Kant, Antbropology, sec. 5). And again: "Innumerable are the sensations and perceptions whereof we are not conscious, although we must undoubtedly conclude that we have them, obscure ideas as they may be called (to be found in animals as well as in man). The clear ideas, indeed, are but an infinitely small fraction of these same exposed to consciousness. That only a few spots on the great chart of our minds are illuminated may well fill us with amazement in contemplating this nature of ours. (Ibid.)

"Now conscious ideas" are such "as are in consciousness without our being aware of them" (Herbart).

It is interesting to note how Kant's statement might well be substituted for that of Myers' of his "Subliminal." It is difficult to appreciate the antagonism of certain modern theoretical psychologists to the theory of subconscious (co-conscious) ideas in view of the history of such ideas in philosophy. They seem to have forgotten their philosophy and not to have kept pace with experimental psychology. 
analytical of the mode of conservation (as physiological residua).

Unfortunately, however, as a matter of fact, as with the philosophers, its use by this school includes that other distinct class of psychological phenomena, which we have every reason to believe to be not unconscious but co-conscious. This use of the term unconscious in philosophy and abnormal psychology to include these two classes of facts has led translators, it would seem, to render Freud's " das Unbewusste" by the English "subconscious" (French " subconscient"). This is only justifiable so long as "the subconscious" and "the unconscious" are each intended to cover both classes; but if "subconscious" is limited, as I have argued it should be, like the French equivalent (Janet), to co-conscious ideas then the rendering of "das Unbewusste" by this English term is indefensible. If, again, the German term is not restricted to physiological residua, great confusion arises and this very confusion, as I have said, underlies the psychopathology of the Freud and Zurich school. The two classes of facts should be very precisely differentiated in our minds, for in a given psychological phenomenon such as the forgetting of a name or an hysterical anesthesia, there is often a grave question whether we have to do simply with a physiological complex without consciousness, or with a coconscious complex. As to the physiological complexes of the spinal cord and ganglia unaccompanied by consciousness, it is evident that they belong to the unconscious of which they constitute a subdivision. These constitute a large part of the manifestations of normal animal life and play an important part in the abnormal life of man.

\section{CHAPTER II}

\section{The Formation of Complexes}

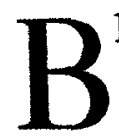

EFORE proceeding to the elucidation of the more specific functions of the unconscious, it will be well

to state in somewhat orderly fashion a few general principles governing the formation of complexes which, as we shall see, play an important part in normal and abnormal life. Although this statement will be little 
more than descriptive of what is common experience, it is well at the outset to classify and arrange the phenomena with which in their many phases we shall deal.

Ideas, then, after being experienced in consciousness, become dormant (conserved as physiological dispositions or residua) and may or may not afterwards be reawakened in consciousness as memories. Many such ideas, under conditions with some of which we are all familiar, tend to form part of our voluntaty or involuntary memories and many do not. But when such is the case, the memories do not ordinarily include the whole of a given mental experience, but only excerpts or abstracts of it. Hence one reason for the fallibilit of human memory and consequent testimony.

Now under special conditions, the ideas making up an experience at any given moment tend to become organized into a system or complex, so that when we later think of the experience or recall any of the ideas belonging to it, the complex as a whole is revived. This is one of the principles underlying the mechanism of memory. Thus it happens that memory may, to a large extent, be made up of complexes. These complexes may be very loosely organized in that the elementary ideas are weakly bound together, in which case, when we try to recall the original experience, only a part of it is recalled. Or a complex may be very strongly organized, owing to the conditions under which it is formed, and then a large part of the experience can be recalled. In this case any idea associated with some element in the complex may, by the law of association, revive the whole original complex. If, for instance, we have gone through a railroad accident involving exciting incidents, loss of life, etc., the words "railroad," "accident," "death," or a sudden crashing sound, or the sight of blood, or even riding in a railroad train may recall the experience from beginning to end, or at least the prominent features in it, i.e., so much as was organized. The memory of the greater part of this experience is well organized, while the earlier events and those succeeding the accident may have passed out of all possibility of voluntary recall.

To take an instance commonplace enough but which happens to have just come within my observation: a fire- 
man was injured severely by being thrown from a hose wagon rushing to a fire, against a telegraph pole with which the wagon collided. He narrowly escaped death. Although three years have passed he still cannot ride on a wagon to a fire without the memory of the whole accident, rising in his mind. When he does so he again lives through the accident, including the thoughts just previous to the actual collision when, realizing his situation, he was overcome with terror, and he again manifests all the organic physical expressions of fear, viz: perspiration, tremor, and muscular weakness. Here is a well-organized and fairly limited complex.

An historical example of this method of formation is narrated in Tallentyre's delightful life of Voltaire. Towards the end of Voltaire's famous residence at the court of Frederick the Great as the latter's guest, one of those pestiferous friends who cannot help repeating disagreeable personal gossip for our'benefit, swore to Voltaire to having heard Frederick remark, "I shall want him (Voltaire) at the most another year; one squeezes the orange and throws away the rind." From that moment a complex of emotional ideas was formed in Voltaire's mind, that, do what he would, he could not get rid of. He wrote about it to his friends, thought about it, dreamed about it; he tried to forget it, but to no purpose; it would not down; the rind kept constantly rising. It brought with it every memory of Frederick's character and actions that fitted the remark. Voltaire, like many men of genius, was a neurasthenic, and his ideas with strong emotional tones tended to become strongly organized and acquire great force. "The orange rind haunts my dreams," he wrote; "I try not to believe it. . . . we go to sup with the king and are gay enough sometimes;- the man who fell from the top of a steeple and found the fall through the air soft, and said, 'Good, provided it lasts,' is not a little as I am."

In psychasthenics and hysterics the sudden suggestion or awakening by whatsoever means of an idea to which a feeling of horror, antipathy, fear or any emotion is attached, readily gives occasion for the formation of such complexes. Mrs. - while in a neurasthenic condition, was carrying in her arms her sister's child (of whom she was very fond) and 
suddenly thought what a horrible thing it would be if she should accidentally drop the child and kill it. From that moment this idea took possession of her mind and recurred invariably whenever in the presence of the child. But more than this, the complex grew, the idea of killing became the dominant thought, and developed into an impulsion to kill the child in spite of her horror of the deed. The complex became enlarged into an elaborate obsession. When this was aroused, like Lady Macbeth, she had visual halluçinations of a knife, a stone, or whatever at the moment was the most handy method of doing the deed. In other respects she was an intelligent, normal, and sane woman, and had a perfectly correct realization of the pathological character of the complex, which she resisted.*

Another psychasthenic, Mrs. B.-, a perfectly moral woman and faithful wife, developed three complexes: one, of a sexual character, was to form immoral and, to her, repellant relations with men whether strangers or not; one to steal money; and the third to kill. The first developed out of a remark made to her by a visitor who casually mentioned that she had observed a number of young women congregating in the neighborbood of a place where many men were employed. The details we need not go into. The second from a thought which flashed into her mind at a moment when she came across some money concealed in a closet; the third apparently from feelings of irritation when annoyed. All three devleoped into fairly large and insistent complexes which became impulsions. The second impelled her to snatch money from the hand of any passenger in a street car whom she chanced to observe. Each of these complexes remained as a compact organized system of thought which recurred and harassed her from time to time and gave rise to many distressing experiences.

Another subject in similar fashion formed a complex which embraced both the impulsion to forge and the fear of doing so.

A patient of Dr. J. J. Putnam's, whom he kindly allowed me to see, developed a complex which had for its

*Boston Medical and Surgical Journal, January 21, 1897. "A Case of Imperative Idea or Homicidal Impulse in a Neurasthenic without Hereditary Taint." 
salient idea that of falling and injuring herself if she walked. As the outgrowth of this complex the patient could not walk without aid, and it was quite ludicrous to see her work her way down stairs, backward, clinging to the banister, as if she was descending from a high and dangerous situation, and as if her life depended upon her grip. With the surging of this complex into her mind there also developed, as is usual in such cases where fear enters as an element, certain physiological accompaniments, the bodily manifestations of the emotions, tremor, palpitation, vasor-motor disturbances, etc.

Clinically the periodic recurrences of such complexes is an obsession. Here I am only considering the conditions of organization and systemization of the complex. From another point of view the recurrence of abnormal complexes represented by these examples may be regarded as an "association psychosis." Sometimes the physiological accompaniments form the greater part of the complex, which is for the most part made up of physiological memories (vasomotor, cardiac, gastric, respiratory, secretory, muscular, etc.), which have few or no conscious correlates; almost pure association neuroses, they then become.

Hay fever, when a neurosis, has been already referred to as an example of such association phenomena. Of course no neurosis is absolutely pure without a psychical element, and vice versa for an association psychosis. In the commonly observed complex of self-consciousness in its various forms, among them that of fear of blushing in the presence of strangers, the psychological and the physiological manifestations are largely conjoined. It is needless to cite further examples of this kind.

There are several other sorts of complexes which differ in certain important respects from the closely organized groups of ideas I have been describing. The latter form little compact nuclei of thoughts, the elements of which are so strongly bound together that they create little whirlpools, so to speak, in the main current of consciousness and are capable of more or less independent functioning. They are apt to produce automatisms (obsessions, insistent ideas, etc.) by which the complex as a whole rushes into activity. The complexes to which $I$ am now referring are rather large 
systems of associated ideas which are intimately related though not compactly organized in the sense in which I have used that expression. Among these systems may here be mentioned those which are related to certain subjects or departments of human experience, or a re related in time, or to certain dispositions or moods of the individual. The first may be called subject complexes, the second chronological complexes, and the last mood complexes.

Subject Complexes: I find myself interested, for instance, in several fields of human knowledge: (a) abnormal psychology; (b) public franchises; (c) yachting; $(d)$ local politics; (e) business affairs. To each of these I give a large amount of thought, accumulate many data belonging to each, and devote a considerable amount of active work to carrying into effect my ideas in each field. Five large complexes are thus formed, each consisting of facts, opinions, memories, experiences, etc., distinct from those belonging to the others. To each there is an emotional tone which has a more or less distinctive quality; that coming from the intellectual interest of abnormal psychology differing qualitatively from that of the " joy of battle" excited by a public contest with a railroad corporation or gas company, as it does from that of the exhilarating sport of a yacht race, or from the annoying and rather depressing care of business interests; and so on.

These five subject-complexes do not form independent automatisms or isolated systems which may intrude themselves in any conscious field, but are large associations bound together, memories of experiences in a special field of thought. Within that field the ideas of a complex are no more strongly organized than are ideas in general; but it can be recognized that the complex as a whole with its emotional tone is fairly well delimited from the other complexes. In certain individuals, at least, it is difficult to introduce the elemental ideas of one subject-complex into another so long as that other occupies the attention of consciousness. Some individuals, too, find it difficult to swing their minds from one subject to another and back again, without waiting for the first subject to subsi $e$. It is said of Napoleon that he had all the subjects of his experiences arranged in drawers of his 
mind, and that he could open each drawer at will, take out any subject he wished, and shut it up again as he wished. Ability of this kind involves remarkable control over the mind and is not given to all.

I have frequently made observations, like the following, on myself: I collect the various data belonging to one of the problems discussed in this work. I arrange all in an orderly fashion in my mind, work out the logical relations and the conclusions to which they lead, as well as their relations to other data and problems. The whole is then schematically arranged on paper to await proper elaboration the next morning, when it will be written out on waking, the preliminary mental arrangement having been done at night. A large complex has been created, the various details of which are luminously clear and the sequence of the ideas vividly conceived, the ccnclusions definite. There is, further, an emotional tone of mild exaltation which is apt to accompany the accomplishment of an intellectual problem and which produces a feeling of increased energy. The next morning, probably owing to the fatigue following the previous night's work, as I awake and gradually return to full consciousness, another and very different kind of complex almost exclusively fills the mind. All sorts of glcomy thoughts, memories of experiences better forgotten, course through my mind, and a strong feeling of depression dominates the mental panorama. The whole makes a complex which has been experienced over and over again and is recognized as such. The same old ideas, thoughts, and memories repeat themselves almost in stereotyped fashion. The mental complex has completely changed and the exuberant energy of the night before has given place to listless inertia. In all this there is nothing remarkable, merely the morning depression to which most people are at times subject, though this depression makes an interesting study from the point of view of mental dissociation and the reproduction of complexes.

But now I remember that I have a task to perform and before rising take paper and pencil lying ready at my side to write out the theme previously arranged in skeleton. But to my surprise I find that it cannot be recalled. To be sure, I can, by effort of will, recall individual facts, but the facts 
have lost their relation and meaning. They remain comparatively isolated in memory, all their correlated ramifications, their associated ideas and relations, which the night before stood out in relief and crowded into the complex, have gone. The emotional tone which bore them into consciousness on the rapid wings of fancy has disappeared, and with it the complex as a whole. It is only by strong effort that I can bring into the focus of attention isolated details. With the fatigue depression a new complex now dominates the mind.

This railure of memory is not that kind of forgetfulness which is due to lack of conservation of new experiences, for the details of the complex were not newly formed last night, but were the gradual growth of prolonged studies of facts and relations with which I had long been familiar. Later in the day, after becoming refreshed by mental exercise, the fatigue and depression disappear, a new energizing emotional tone arises and the sought for complex returns in its entirety. With this change the depression complex in turn disappears, and now it is difficult to recall it, excepting that, as an intellectual fact, I remember that such a complex occupied my mind in the early morning hours. The two complexes as a whole are distinctly dissociated from one another.

Another example could be cited in the plans of a yacht I am building, in anticipation of projected races. So vivid are some of the ideas that with my eyes closed and in the dark I actually visualize the boat in all its details. The next morning this complex has vanished like the other and cannot be recalled except in a scrappy way.

This is only expressing in some what technical language a common experience, as most people, I suppose, have such alternations of complexes. The facts are trite enough; but, because it is common experience, it is well to formulate the facts and so, as far as possible, give precision to our conception of the psychological relations which have a distinct bearing on the principles of dissociated personality and other psychoses, character, and psycho-therapeutics. When, at a later time, we take up for study the subject of dissociated personality we shall find that the dissociation of consciousness sometimes takes its lines of cleavage between complexes of 
this kind. And above all, the principle of the formation of complexes is the foundation stone of psycho-therapeutics.

Varieties of this mode of organizing mental processes are the methods of education and suggestion. Both, in principle, are substantially the same, differing only in detail. They depend for their effect on the implantation in the mind of ideational complexes which, by repetition, become organized. Every form of education necessarily involves the artificial formation of such complexes, whether in a religious, ethical, scientific, social, or professional field. By artfully directed suggestion in the narrower sense - for suggestion, broadly considered, is a form of education - complexes may be similarly formed and organized. Ideas of right or wrong, of jealousy or sympathy, of hatred or love, are awakened, all their associated emotions are aroused, and the whole welded into a complex. Under ordinary conditions of everyday mental life, ideas so originated necessarily become mingled with the stream of the personal consciousness, so that only the color of the stream is modified without altering the smoothness of the current. A new tint, only, is given to the mixture. But sometimes the new ideas retain their organization, fail to mix, and persist as well-defined 'complexes, like vortices in the current. Later, when the ideas pass out of mind and become dormant, these complexes still persist as physiological organizations and remain capable of recall.

Chronological complexes are those which embrace the experiences of certain epochs of our lives regardless of the subject material included in them. In a general way events, as they are successively experienced, become associated so that the experiences of an epoch tend to be conserved en masse. The later recollection of one event of an epoch recalls successively the others. This is an axiom of memory. The principle, however, plays an important part in abnor al conditions in that, in certain states in which there is a dissociation of personality, or amnesia, the cleavage of memory may be along chronological lines; that is to say, the amnesia embraces a certain epoch only. The newly integrated per- 
sonality goes back to the period last remembered in which he believes, for the moment, he is still living, the memory of the succeeding last epoch being dissociated from the personal consciousness.

Disposition or Mood Complexes: Amongst the loosely organized complexes in many individuals, and possibly in all of us, there are certain dispositions towards views of life which represent natural inclinations, desires, and modes of activity which, for one reason or another, we tend to suppress or are unable to give full play to. Many individuals, for example, are compelled by the exactions of their duties and responsibilities to lead serious lives, to devote themselves to pursuits which demand all their energies and thought and which, therefore, do not permit of indulgence in the lighter enjoyments of life, and yet there may be a natural inclination to partake of the pleasures which innately appeal to all mankind and which many pursue. The longing for these recurs from time to time. The mind dwells on them, the imagination is excited and weaves a fabric of pictures, thoughts, and emotions which thus become associated into a complex. There may be a rebellion and "kicking against the pricks" and thereby a liberation of emotional force that impresses a stronger organization on the whole process. The recurrence of such a complex is one form of what we call a " mood," which has a distinctively emotional tone of its own. The revival of this feeling tone tends to revive the associated ideas and vice versa. Such a feeling-idea complex is often spoken of as "a side to one's character," to which a person may from time to time give play. Or the converse of this may hold, and a person who devotes his life to the lighter enjoyments may have aspirations and longings for more serious pursuits, and in this respect the imagination may similarly build up a complex which may expross itself in a mood. Thus a person is often said to have "Iany sides to his character," and exhibits certain alternations of personality which may be regarded as normal prototypes of those which occur as abnormal states.

Undoubtedly in the development of moods with their 
respective complexes an alteration in the coenesthesis of the individual may play a part. By coenesthesis is meant the combination of all the organic sensations which stream into the sensorium from the different organs of the body, from the viscera, the muscles, the skin, etc. All these organic sensations without question play a large part in personality, particularly in the formation of feeling tones and, therefore, moods; the feeling of well-being and of vitality undoubtedly depends, at times at least, upon normal coenesthesis, and, conversely, the feeling of depression and lowered vitality upon alterations in the coenesthesis. These organic sensations tend to determine their corresponding mental complexes and thus direct the current of ideas. Ribot would make of coenesthesis a predominant factor in personality. Without laying as much weight as does this writer upon this factor, we can, nevertheless, ascribe to it its just weight as a contributing factor; but the converse is also true that the excitation of particular mental ideas determines the corresponding feeling tone and coenesthesis.

It may be interesting to note in passing that the wellknown characteristics of people of a certain temperament, in consequence of which they can pursue their respective vocations only when they are " in the mood for it," can be referred to this principle of complex formations. Literary persons and artists in whom "feeling" is apt to be highly cultivated are conspicuous in this class. The ideas pertaining to the development of their craft form mixed subject and mood complexes which tend to have a strong feeling tone. When some other feeling tone is substituted, having itself a corresponding complex, it is difficult for such persons to revive the subject complex belonging to the piece of work in hand, and necessary for its prosecution. "The ideas will not come," because the whole subject complex which supplies the material with which the imagination is to work has been dissociated and replaced by some other. Certain elements in the complex can be revived piecemeal, as it were, but the complex will not develop in mass with the emotional driving energy which belongs to it. Not having their complexes and feelings under voluntary control it is necessary for such persons to wait until, from an alteration in the coen- 
esthesis or for some other reason, an alteration in the feeling has taken place with a revival of the right complex in mass.

Most of what has been said about the formation of complexes is a statement of commonplace facts, and I would not repeat it here were it not that, in certain abnormal conditions, disposition, subject and other complexes, though loosely organized, often play an important part. This is not the place to enter into an explanation of dissociated personality, but I may point out, in anticipation of a deeper discussion of the subject, that in such conditions we sometimes find that disposition complexes, for instance, come to the surface and displace or substitute themselves for the other complexes which make up a personality. A complex which is only a mood or a "side of the character" of a normal individual may, in conditions of dissociation, become the main, perhaps sole, complex and chief characteristic of the new personality. In Miss Beauchamp, for instance, the personality known as B I was made up almost entirely of the religious and ethical ideas which formed one side of the original self. In the personality known as Sally we had for the most part the complex which represented the enjoyment of youthful pleasures and sports, the freedom from conventionalities and artificial restraints generally imposed by duties and responsibilities. In B IV the complex represented the ambitions and activities of practical life. In Miss Beauchamp as a whole, normal, without disintegration, it was easy to recognize all three dispositions as " sides of her character," though each was kept ordinarily within proper bounds by the correcting influence of the others. It was only necessary to put her in an environment which encouraged one or the other side, to associate her with people who strongly suggested one or the other of her own characteristics, whether religious, social, pleasure loving, or intellectual, to see the characteristics of B I, Sally or B IV stand out in relief as the predominant personality. Then we had the alternating play of these different sides of her character.

Likewise in Bertha A. In each of the personalities, B and $A$, similar disposition complexes could be recognized, each corresponding to "a side of the character" of the original personality $C$. In $A$ was represented the complex 
formed by ideas of duty, responsibility, and moral scruples; in $\mathrm{B}$ was represented the complex formed by the longing for fun and the amusements which life offered. When the cleavage of personality took place it was between these two complexes, just as it was in Miss Beauchamp between the several complexes above described. This is well brought out in the respective autobiographies of B and Sally in these two cases. In many cases of hysteria in which dissociation of personality can be recognized, the same phenomenon is often manifest. Likewise a careful study will reveal it, I believe, in other cases of multiple personality, although, of course, the dissociation may be along other lines; that is, between other complexes than those of disposition.

COMPLEXES MAY BE FORMED IN HYPNOTIC AND OTHER DISSOCIATED CONDITIONS OF THE PERSONAL CONSCIOUSNESS

We have been speaking thus far of complexes formed in the course of every-day life and which take part in the composition of the normal personality. But it is obvious that a complex may be organized in any condition of personality so long as consciousness, however limited or disturbed, is a part of it. Thus we may find one or more complexes in artificial states like hypnosis and those pathological conditions in which there is a splitting of personality, a disappearance of a large part of the normal mental life, leaving only a limited field of consciousness and perhaps a new synthesis to represent the personal self. Hysterical crises, psycholeptic attacks, dreams, trance, certain types of epilepsy, etc., may be instanced as illustrative examples. Solong as any of the elements of consciousness are capable of functioning, so long as any ccnsciousness exists, the elements of this consciousness may be organized into a complex, and with the reproduction of the given pathological state this complex may recur, or, as is often the case, the re-excitation of the complex may reproduce the state, whether psycholeptic, hysterical, or some other. Thus it is that this principle of complex-formation, as we shall see, plays a prominent part in certain psychoses. The greater the limitation of consciousness, the fewer the ideas, perceptions, and other conscious elements left, the more 
strongly organized and more circumscribed are the elements of the complex. Hence, in such states, if a complex has been formed, the ideas repeat themselves over and over again with the recurrence of the attacks. The subject lives over again as in a dream the original attack, which is a stereotyped revivification of the original experience. This peculiarity of the mental condition in attacks has been described by various writers. The dream of the hystero-epileptic is substantially always the same. In the psycholeptic the same sensations or hallucinations and the same bizarre ideas characterize each attack. M-l, who has frequently been referred to,* in each hysterical attack lived over again the original experience when he was frightened on a lonely road at night and manifested the same physical phenomena which accompanied the fright.

Likewise in hypnosis the memories of past hypnotic experiences may, by suggestion or constant repetition, be welded into a complex. On regaining the normal condition the personal self may, and if the dissociation was sufficiently great frequently does, have complete amnesia for the complexes of the artificial state. But the memory of them is conserved and is reproduced with the return to the given state. The principle involved in what I here only touch upon occupies so important a place in the psychoses that it needs to be thoroughly studied, but as I shall have occasion to return to it I may defer for the present further elaboration.

\section{THE COMPOSITION OF DORMANT COMPLEXES}

The composition of dormant complexes is of practical importance. No idea ever becomes a part of our mental experience in an isolated form. Every idea occurs concurrently or in series with a large variety of other experiences which are both psychological and physiological. Along with any single idea at any given moment - as, for example, the

*In a forthcoming work on the Subconscious, see also, Boston Medical and Surgical Journal, June 23, 1904 (Pathology of Hysteria; Sidis, Prince \& Linenthal). For illustrative cases compare Prince \& Coriat, Jour. And. Psychol., Oct.-Nov., 1907. Sidis, Boston Med. and Surg. Jour., March 28,1907 . 
recognition of an imminent accident or the thought of a possible line of conduct - there arise numerous associated ideas, memories, and language symbols of ideas, with feelings, whether of fear, or anxiety, or well.being, or joy, etc. There also pour into the mental complex a number of visual, auditory, and other perceptions of the environment; muscular, visceral, and other sensations of the body (coenesthesis), a class of reactions which are purely physiological. Amongst the latter, for instance, may be incluc ed increased action of the heart, increased or diminished secretions of the body (saliva, perspiration, etc.), alterations in the respiration, and so on. These physiolcgical reactions again may awaken more or less conscious perceptions of their functioning. The exact mechanism by which these physiological reactions are excited with, or by, ccnscious mental experiences is only incompletely known, but the fact remains that they do occur and and by repetition develop into physiological memories. All or many of these experiences, psychological and physiological, may take part in the formation of a psycho-physiological complex which, later, is to become dormant and conserved as physiological residua.

I Thus neuroses as well as psychoses originate and are conserved. The former are the resultant of physiological memories, as detailed in the preceding chapter. In further illustration I may mention the case of Miss T., who suffers from a peculiar but common psycho-neurosis, the basis of which is abnormal self-consciousness. When in the presence of people - particularly, though not necessarily, strangers an attack characterized by the following symptoms develops: excessive blushing of the face; feeling of heat throughout the entire body; pain along the spine, and great physical discomfort. This is followed, as the attack goes off, by marked general perspiration, pallor of face, general exhaustion, and dyspeptic disturbance. These physical symptoms are the sequence of and depend upon a certain preceding mental complex which is regularly excited under the above conditions. It is consciousness of self - that she is the object of observation and criticism because of her infirmity of which she is ashamed. This idea naturally brings other distressing thoughts in its train, the whole causing much mental pain 
and unhappiness. The psychical and physiological elements of this $s y$ ndrome have become woven into a complex which repeats itself on each favorable occasion. Sometimes even when alone; if her thoughts dwell upon herself, the syndrome will be awakened. It can easily be imagined that life had become burdensome and restricted.

It is needless to give further examples of such psychoneuroses which occur in every conceivable form. I have given various instances in the case of Miss Beauchamp.* They have been frequently described in medical literature. It is important, however, that the psychological principles underlying them should be understood, particularly as they offer a favorable field for psycho-therapeutics especially productive of results.

\section{THE CONSERVATION OF COMPLEXES}

The point that I am leading up to is this: How comes it that ideas are welded into complexes which reappear as organized memories? What is it that binds the mental experience of an emotional railroad accident or an obsession, or of a subject or mood complex, or whatever kind of association it be into a system? The answer must be sought in the neuron system, not in the mind. On the theory of physiological residua it is plain. We have seen in the last chapter that the theory of memory depends upon the inditing of physiological records of our ideas through the impression of residua or "dispositions" in the neurons of the brain; the ideas of the moment pass out of mind, but the records still persist, capable of functioning again and manifesting themselves as conscious memories corresponding to the original conscious complex. We must assume that the cerebral neuron dynamics have become organized into a physiological complex which retains its organization as such. Our conscious experiences, besides leaving residua corresponding to each conscious element, leaves them all linked into systems an association system or physiological complex. So that when one element in the physiological complex is stimulated the whole organized process is set going, and with this the

*"The Dissociation of a Personality." pp. 22, 65, 262. 
conscious complex (memory complex). In the spinal column and ganglia, where physiological complexes are formed and reproduce physiological reactions or memories without consciousness, this principle is accepted as the only one capable of explaining the reaction resulting from education. Indeed functioning of the unconscious neuron systems is unintelligible except on this theory. The spinal column and ganglia are capable of acquiring extremely complicated reactions (memories) known as compound reflexes (e.g. those of perverted visceral, vasomotor, and muscular functions). The mechanism of the brain must be the same, though more complicated, and the organization of cerebral complexes must follow the same laws as those of the lower neuron centers. Our anatomical and physiological nomenclature tacitly assumes this mechanism. "Association tracts," "reflex process," "synergesis," "synapsis," "inhibition," etc., all testify to this assumption.

In passing I may point out that observation shows that emotion is a powerful factor in establishing physiological dispositions (residua and organization). The experience of a railroad accident, for example, accompanied by intense fright, is prone to be left as an indelible impression which may, in certain individuals, be aroused from time to time as a psychosis or obsession. It would seem, using metaphor, that emotions were a force which makes more intense dynamic changes, cuts the records deeper, as a loud voice magnetizes more intensely the wire of a phonograph or cuts the record in the wax cylinder more deeply. The records of our lives, then, are written in unconscious dormant complexes and there conserved so long as the residua retain their dynamic potentialities. It is the unconscious, rather than the conscious, which is the important factor in personality and intelligence. The unconscious is the storehouse of our minds. The secret of our moods, our impulses, our intelligence, our acquisitions, our attitudes, our judgments, our capacities, is to be found in its conserved dispositions.

In the second place the records of our experiences may be retained though we cannot voluntarily recall them. This is shown experimentally by the fact that through special devices (hypnotism, abstraction, automatic writing, 
etc.), and in special states (dreams, trances, etc.), memories of experiences long forgotton and beyond the possibility of recall by voluntary effort, may be revived. On the other hand, as every one knows, a memory complex which at one moment cannot be voluntarily recalled and is apparently lost, may at another be so regained when the mental conditions are favorable and proper stimulus is applied.

In the third place it is evident, and this is confirmed by observation, that it matters not in what state the complex was originally experienced, whether in the consciousness of the normal personal self, or in an artificial state like hypnotism, or pathological states like dissociated personality, or hysterical crises, or what not; the physiological residuum remains ready to reproduce the original experience (memory) in whole or in part when the favorable occasion arises. Whether the corresponding memories are to be reproduced or not depends on special conditions. They may remain organized and dormant for years, as integral elements of our personality, long after they have passed out of voluntary recall. Even in functional amnesia for epochs, the entire mental experiences, though they cannot be recalled, are conserved in the unconscious dormant consciousness, ready to be brought back as conscious memories by suitable devices or under favoring conditions. All conscious experiences, in whatever state and however conserved, so long as retained in the unconscious, are part of ourselves and may again play a part in our lives. This is not to say that all physiological residua are indefinitely conserved. On the contrary, probably the greater number undergo dissolution in time and disappear. But any one may be conserved for an indefinite period, as I shall point out in the next chapter.

In the fourth place it is evident that, theoretically, unconscious complexes once formed, may, under favoring conditions of the psycho-physical organism, become revived and play an important part in pathological mental life. Theoretically, if freed from the normal inhibition and the correcting influences of the normal mental mechanism and given an independence and freedom from voluntary control, they might, by functioning, produce abnormal states like fixed ideas, delusions, automatisms, hallucinations, etc. A study 
of such abnormal phenomena confirms this theoretical view and finds in this conception of the unconscious an explanation of their mechanism. Even in the bizarre notions and delusions of the insane, where all seems chaos, without law or order, Jung, in one disease at least (dementia precox) finds the resurrection of unconscious complexes formed by the earlier experiences of the patient's life.

Finally, and this is a point of the highest importance for psycho-therapeutics, however intensely organized a complex may be conserved and be retained in consciousness, so long as the individual is in other respects normal (sane), it may be modified by the introduction of new ideas into the complex (education). Thus by a process of substitution and addition our personality may be altered for good or ill.

In the conservation of mental experiences as physiological residua we have a psycho-physiological mechanism which renders intelligible the influence which, according to Freud, " suppressed ideas " exert in shaping and determining the mental processes of every-day life, as well as in pathological conditions. Freud, it will be remembered, insists that, with great frequency, the apparently accidental forgetting of names, and substitution of wrong words, the apparently voluntary selection of numbers, the determination of the details of dreams, etc., are not due to chance, and causeless, but are directed by the automatic influence of suppressed unconscious ("subconscious"?) memories, and claims by the method of psycho-analysis to be able to reveal these unconscious memories. Without accepting the entire correctness of this theory, there is no doubt that many of our apparently self-determined processes of thought are really the resultant of previous mental experiences which have long passed out of mind. In post-hypnotic phenomena we have evidential examples of this principle. In the theory of the dormant consciousness we have a mechanism quite sufficient to afford a basis for all such phenomena.

THE DORMANT CONSCIOUSNESS LARGELY FORMED BY THE SIFTED EXPERIENCES OF OURSELVES AND OUR

PREDECESSORS

As mentioned at the beginning, all mental experiences are not organized into complexes, but, after they have served 
their purpose for the moment, are dissipated just as printers' type is dissipated or distributed after it has served its purpose in printing. Whether or not a given experience shall become organized depends on various factors, among which the most effective are repetition, and the intensity of the accompanying emotional tone.

But the elements of such experiences may persist as unconscious physiological residua and be still capable of voluntary or involuntary recall. Such elements probably make up the larger part of our memories and tend to shape the judgments, the beliefs, convictions, and trend of our mental lives. In fact, the total of our complexes, which, regarded as a whole and in view of their reaction to the environment, their behavior under the various conditions of social life, their aptitudes, feeling-tones, "habits," and faculties, we term character and personality, are in large part predetermined by the mental experiences of the past and the vestiges of memory which have been left as residua from these experiences. We are the offspring of our past. The elements of the mental experiences of any given moment become sifted, as it were; the unessentials and useless, the intermediate steps leading to the final and useful, drop out without leaving conscious vestiges, while the essential and useful remain as memories capable of recall from the dormant consciousness. Here they remain more or less permanently fixed as single ideas or simple complexes. Whence they came, how they were born, we have long ceased to remember, but we are all plagiarists of the past, of our own and of that of others. We often arrive at conclusions which, we imagine in our ignorance, we have constructed unaided out of our inner consciousness. In one sense this is true, but that inner consciousness has been formed largely out of vestiges furnished by the forgotten experiences derived from others, and we are surprised later to find the source of our innocent plagiarism.

Through education, whether scholastic or social, we inherit the experiences of our predecessors. The conceptions of one age never can represent those of a preceding age. The veriest layman in science to-day could not entertain the conceptions underlying many hypotheses formulated by the wisest of the preceding age, of a Galileo, a Descartes or Pascal. 
Lucretius, in the first century B.C., argued with what for the times was great force, that the soul of man was corporeal and that it " must consist of very small seeds and be inwoven through veins and flesh and sinews; inasmuch as, after it has all withdrawn from the whole body, the exterior contour of the limbs preserves itself entire and not a tittle of the weight is lost." Lucretius gave much thought to this problem, but to-day the least informed persons, who have never reflected at all on psychological matters, would reject the hypothesis, and recognize the foolishness of such a conception.* They would call it commonsense which guided them, but commonsense depends upon the fact that in the dormant consciousness lie memories, the reasons for and origin of which we do not remember, that nullify such an hypothesis. These contradictory ideas, sifted out of those belonging to the social education, have become fixed as dormant or organized memories and determine the trend of the personal consciousness. These memory vestiges may work for good or evil, shape our personal consciousness into a useful or useless form, one that adapts or unfits the organism to its environment. In the latter case they drive it into the field of pathological psychology. The effect of this we shall see in studying the behavior of compact complexes which have a similar origin and influence. These latter, having a grosser form, are more obtrusive, more readily recognized within the current of our conscious life, and are more easily studied; for the sifted elements of mental experience, of the kind we have been speaking of, are not, like these latter, organized into definite circumscribed complexes so as to form a coherent nucleus of ideas. A simple observation which any one can make on himself enables us to recognize the extent to which our conscious experiences may be conserved in the unconscious without our being able to voluntarily revive them. If after reading a book or chapter in a book, we put it aside for awhile, we find later, on taking it up, that we are unable to

\footnotetext{
*Prof. G. S. Fullerton, in the course of an essay, |"Is the Mind in the Body," interestingly refers to this fact and points out that commonsense directs the common man in repudiating ancient doctrines, and that it is "part of his share in the heritage of the race." "The commonsense which guides men is the resultant attitude due to many influences, some of them dating very far back indeed." The Popular Science Monthly, May, 1907.
} 
recall to any appreciable degree the contents of the chapter. It may be practically blank. Now on rereading it we find not only the facts familiar, but almost each sentence. This can only mean that the experiences of the first reading were conserved in the unconscious and are now revived by the stimulus of re-reading. It is evident that the conserved ideas might be revived by other stimuli (associated ideas) without our being aware of their original source owing to a failure of complete organization of the ideas of the book, sentences, authorship, etc., among themselves.

In succeeding chapters the specific influences of the unconscious will be considered in some detail.

(To be continued) 